\title{
Formação do professor para o uso das tecnologias digitais
}

Teacher training for the use of digital Technologies

\author{
Janúzia de Nazaré Santos ROMÃO* \\ Universidade Federal de Lavras (UFLA) \\ Patrícia Vasconcelos ALMEIDA** \\ Universidade Federal de Lavras (UFLA)
}

RESUMO: Este artigo objetiva suscitar a reflexão do professor, sobretudo professor de Língua Inglesa, para o uso das tecnologias digitais como artefatos pedagógicos. Trata-se de uma pesquisa de campo, logo é um estudo de caso, que analisou as práticas pedagógicas de quatorze professores de sete escolas públicas do sul de Minas Gerais. Os resultados apontaram que os professores ainda apresentam dificuldade em se apoiarem nas tecnologias digitais como mediadoras do ensino e quando o fazem não demonstram segurança para suas escolhas. Há evidências da fragilidade na formação inicial e continuada desses professores. Logo, o presente trabalho apresenta em seu desfecho o esboço de uma oficina aos professores participantes, com o intuito de contribuir com a formação crítico reflexiva em torno da utilização das tecnologias digitais como artefato pedagógico.

Palavras -chave: formação continuada; práticas pedagógicas; artefatos tecnológicos

\begin{abstract}
This article aims to promote a reflective thinking from language teachers about the use of digital technologies as pedagogical artifacts. This is a field research, which is a case study, and it analyzed the pedagogical practices of fourteen teachers from seven public schools in the south of Minas Gerais. The results showed that teachers still find it difficult to rely on digital technologies as mediators of language teaching, and when they do, they do not demonstrate security for their choices. There is evidence of the fragility in the initial and continued formation of these teachers. Therefore, the present work presents in its conclusion the
\end{abstract}

\footnotetext{
* Mestre em língua inglesa pela Universidade Federal de Lavras (UFLA). E-mail: janusiaromao75@gmail.com

${ }^{* *}$ Doutora,Professorade Lingua Inglesa na Universidade Federal de Lavras (UFLA). E-mail: patricialmeida@ufla.br
} 
outline of a workshop to the participating teachers, with the purpose of contributing to the reflexive critical formation around the use of digital technologies as pedagogical artifact.

Keywords: ongoing teacher education; pedagogical practices; technological artifacts

\section{Introdução}

O presente artigo tem como escopo um trabalho investigativo sobre a formação de professores e levanta a hipótese de que os professores de Língua Estrangeira (LE) Língua Inglesa (LI) - ainda não utilizam as tecnologias digitais de informação e comunicação (TDIC), de forma crítico-reflexiva, em suas práticas diárias. Essa hipótese surge da experiência profissional da pesquisadora que, como professora de LI da rede pública, há mais de vinte anos compartilha da ideia que preconiza a necessidade de uma formação continuada para os professores de LI.

Esse artigo tem como mote a formação docente tendo como desafio o trabalho didático-pedagógico em uma sociedade globalizada, com suas práticas dependentes da tecnologia digital. Desta forma, buscamos contribuir para a área de CALL (sigla em inglês usada para Aprendizagem de Línguas Mediada pelo Computador) e de formação do professor de línguas ao relacionar o uso da tecnologia digital com a formação (inicial e continuada) de professores de línguas.

De acordo com Levy (1997), a realidade tecnológica na qual está imersa a escola, demanda saberes, percepções e práticas por parte dos professores de LI de forma diferenciada das tradicionais que regiam o processo de ensino-aprendizagem. Segundo Sampaio e Leite (2011), o professor precisou passar do estágio de "alfabetizado tecnológico" para o desenvolvimento de um letramento digital que envolva, não só as habilidades técnicas de uso do computador conectado à rede, mas também, a percepção de que o contexto histórico social em que ele está inserido demanda novas práticas digitais dentro da sala de aula (BRAGA, 2013).

Por essa razão, consideramos que a ampliação do conhecimento operacional e funcional dos artefatos tecnológicos de forma critico-reflexiva pode vir a favorecer a tomada de decisão do professor em relação à multiplicidade de artefatos tecnológicos que podem ser utilizados no seu contexto escolar. E dessa forma, pode vir a modificar, 
significativamente, o ensino de uma língua estrangeira (LE) nas escolas públicas. (CHAPELLE, 1990; VETROMILLE, 2003; BRAGA, 2004; COSCARELLI, 2011).

Após o exposto, passamos a uma apresentação mais detalhada do escopo teórico da investigação, sua metodologia, um recorte dos resultados obtidos, que embora sejam locais, podem vir a suscitar uma reflexão cuidadosa em outros contextos. O texto apresenta ainda, em sua seção de análise e discussão, um esboço de uma oficina a ser implementada para os sujeitos colaboradores na geração de dados.

\section{Formação do Professor para o Uso das Tecnologias Digitais}

Diante da realidade contemporânea tecnológica em que vivemos parece improvável discutir formação de professores sem mencionar a utilização das tecnologias digitais voltada para o contexto de ensino-aprendizagem. Segundo Lévy (1999), estamos imersos no mundo tecnológico, e essa involuntária imersão convida-nos a pensar em uma reconstrução de posturas didático-pedagógicas em sala de aula, para além das práticas que envolvem apenas atividades de memorização e técnicas que prescrevem respostas exatas e definitivas. Nesse sentido, defende-se que o professor deva ter uma preparação, inicial e continuada, que o exponha ao uso de artefatos tecnológicos de forma consciente e crítica em suas práticas pedagógicas.

Vale ressaltar que o incentivo para o uso das tecnologias digitais ou não, durante o período de formação, seja ela inicial ou continuada, deve ser embasado em teorias que justifiquem e fundamentem uma prática que se desenvolva para além de apenas transferir o material impresso para o meio digital ou apenas utilizar a tecnologia por questão de modismo. Face ao exposto, é preciso lembrar que o ensino de línguas, atrelado ao uso das tecnologias digitais, já é tema de vários estudos da área de formação de professores, há várias décadas. Dentre os autores que tratam dessa questão, destacam-se Chapelle (1990) e Lévy (1997).

Segundo Chapelle (1990, p. 199) "os professores precisam entender como CALL podem ser melhor utilizados para oferecer uma efetiva aprendizagem aos alunos". Essa ponderação da autora nos leva a evidenciar a importância do processo formativo do professor. Pois, acreditamos que é nesse processo que ele irá ter noções formais e teóricas sobre como utilizar devidamente as tecnologias digitais para o 
contexto de ensino, visto que a área de atuação da autora - Aprendizagem de Língua Mediada pelo Computador $=$ Computer Assissted Language Learning (CALL) - tem como escopo abordar as nuances sobre o processo de aprendizagem de línguas mediado pelo computador.

Relativo a essa questão, vale elucidar que o caráter formativo do professor pode ser construído ao longo de seu processo como educador. Não obstante, todos os entraves e desafios vivenciados pelos professores, podem ser superados se ele estiver disposto a mudar suas práticas e buscar aprimoramento de seus afazeres. Desta forma, ele se colocará mais aberto às mudanças e indagações nesse contínuo processo de reconstrução. Nesse sentido, é possível inferir sobre um possível crescimento profissional dos docentes, por meio das pesquisas na área da Linguística Aplicada (LA), assim como afirmam Kleiman e Moraes (2013, p.100):

\begin{abstract}
$\mathrm{O}$ fortalecimento acadêmico alcançado progressivamente a partir da pesquisa em LA na área de formação de professores. Percebe-se o caminhar da noção de treinamento em direção às noções de educação, formação, desenvolvimento profissional Charlot (2005), Machado (2004), Romero (2010), Szundyetal (2011), Telles (2009), dentre outros; da busca pela eficiência a partir da subserviência às abordagens e métodos prescritos em direção à criticidade e à ética na época "pós-método" Celani (2005), Magalhães e Fidalgo (2011), Moita Lopes (2006, 2009), Silva et al. (2012), dentre outros.
\end{abstract}

Em face do exposto, podemos ressaltar a característica indagadora e reflexiva dos pesquisadores da área, que parecem buscar, em contextos de formação de professores, uma constante reconstrução do "ser professor" de forma reflexiva e contextualizada. O que nos leva a considerar a necessidade de formar professores dispostos a considerar mudanças em relação à suas práticas, mesmo com todos os desafios enfrentados pela docência, especificamente o ensino de LI, em seus múltiplos contextos sociais.

Como o escopo deste artigo envolve o uso das tecnologias digitais para o ensino de LI, na próxima seção apresentaremos um pouco sobre alguns trabalhos desenvolvidos na área de CALL para elucidar possíveis recursos tecnológicos mediadores do ensino da LI.

\title{
2. Contribuições da área de CALL para o ensino da LI
}


$\mathrm{Na}$ área de LA, muito se tem discutido em relação ao uso das tecnologias digitais para o ensino da LI. Vale nesse momento justificar nossa opção em ter como aporte teórico os preceitos de CALL em sua amplitude visto que, segundo Hubbard (2004), os estudos nessa área possibilitam avaliar o comportamento e a tomada de decisões de professores durante o processo de planejamento e execução de atividades para o ensino mediado pelo computador. O termo CALL foi consagrado por escritores como Levy e Hubbard (2005) como o termo mais inclusivo para a area de conhecimento que envolve os processos de ensino-aprendizagem de línguas por abarcar todas as variáveis de uso de tecnologias - digitais ou não - destes estudos.

Além disso, é importante destacar que a investigação que sustenta esse artigo é facilmente incorporada na área de conhecimento que envolve os preceitos de CALL, pois lida com a importância de se inserir o computador conectado à internet, como ferramenta didática. Por esta razão, os trabalhos a serem apresentados abaixo servem de subsídios teóricos iniciais para despertar o interesse de investigação no contexto acadêmico de formação de professores de LE.

Começaremos com um trabalho de Doutorado de Ana Carolina Simões Cardoso (2015) que investigou a prática de uma professora regente, em relação ao uso das TDIC tendo alunas estagiárias em sua sala de aula. Em sua pesquisa, Cardoso (2015) buscou salientar o aporte prestado pela professora regente às graduandas e a partir dos resultados buscou sugerir práticas diferenciadas, para o uso das TDIC, no contexto de formação inicial de professores. De acordo com o trabalho, várias propostas de sites e recursos da internet para serem aplicados em salas de aula do ensino médioforam apresentadas às estagiárias. A cada nova proposta, as seis graduandas e professora regente se reuniriam para discutir os resultados.

O primeiro deles foi o site Global Warming, Plataforma Moodle. O objetivo do uso da Plataforma Moodle, nesse caso, foi para desenvolver a habilidade escrita dos alunos (Cardoso, 2015). O segundo recurso foi o uso do Google, com o objetivo de orientar os alunos a pesquisarem, no ambiente virtual, nesse caso especifico, a professora sugeriu Natural Disasters e apresentou um roteiro. Os alunos deveriam buscar apenas o local do ocorrido, quando e quais as consequências de tal acontecimento. A terceira sugestão relacionou-se aos sites www.breakingnewsenglish.com e www.newsmap.jp. Vale ressaltar que o Newsmap é 
um site japonês que mostra diversas manchetes de portais de notícias do mundo inteiro. As manchetes são divididas por categorias (mundo, nacional, negócios, tecnologia, esporte, entretenimento e saúde) por meio de diferentes cores.

O trabalho de formação inicial, proposto por Cardoso (2015) junto às licenciandas do curso de Letras, pode ser considerado como paradigma de formação para atuação de futuros professores no contexto escolar para o uso das TDIC. As discussões ocorridas no grupo, em torno da utilização pedagógica das tecnologias digitais e de seus respectivos resultados trata-se de uma prática defendida (SANTOS, 2012) como forma de fundamentar o uso das tecnologias digitais. Logo, conforme (BAX, 2003, 2011; VIEIRA, 2010), se não houver formação do profissional da educação, pouco valerão os investimentos em recursos tecnológicos.

Em relação à essa assertiva, devemos pontuar que a formação inicial ou continuada do professor para a área de CALL parece ser um diferencial para uma prática contundente de ensino da LI. Nessa ótica, destacamos mais uma experiência, por meio da dissertação de mestrado de Wallace Moura da Costa (2014). Tendo como contexto escolar uma escola Municipal, o pesquisador pontua como objetivo geral a inserção das TDIC, no ensino da LI na Escola Municipal e a observação das possíveis mudanças ocasionadas pelo uso das tecnologias digitais como recurso pedagógico mediador do ensino.

Em uma tentativa de promover propostas de aprimoramento de ensino e aprendizagem de LI, visando confirmar a importância do uso das TDIC nas aulas, o professor e pesquisador faz uso dos sites www.inglesnanet.weebly.com, LiveMocha, SharedTalk, Babbel, Italk, Busuu etc. (gratuitos) e Englishtown, OpenEnglish etc. (pagos). O professor almejava tornar diferenciado o ensino da LI, naquele contexto escolar, em que, até então, somente as tecnologias tradicionais, i.e. livro didático, lousa, giz e a voz do professor eram mediadoras do ensino da LI, mesmo a escola disponibilizando recursos como "uma sala com projetor, 20 computadores conectados na internet, DVDs, CD player e impressora" que poderiam ser utilizados na proposição de um trabalho diversificado (COSTA, 2014, p. 74).

Sobre a não utilização dos artefatos pedagógicos, especialmente, de forma fundamentada, Chen (2008) afirma que se trata de um fato peculiar aos professores de 
LI de escolas públicas, independente do tempo de atuação. Nessa perspectiva, Baptista (2014, p. 9) salienta:

Que não é suficiente pressupor que professores em
formação, mais jovens, que fazem uso de novas tecnologias em seu cotidiano,
saberão utilizá-las pedagogicamente. Todos os participantes que apontaram
que não sabiam como utilizar as novas tecnologias trabalhadas na disciplina
(redes sociais, blog, podcast, wiki, dentre outras) para fins pedagógicos
tinham, na época em que os textos foram redigidos, 21 anos, ou seja, apesar
de jovens e de estarem em constante contato com tecnologias, eles não
conseguem necessariamente pensar em um uso pedagógico dessas
ferramentas.

Em relação ao conteúdo da citação supramencionada, devemos inferir que não basta o contato direto com os artefatos tecnológicos digitais, para ser capaz de promover um trabalho pedagógico voltado para o ensino da LI. É necessário que o educador aprimore seus conhecimentos teóricos, a fim de promover escolhas tecnológicas digitais fundamentadas e com objetivos claros e precisos. Essa maturidade pedagógica, por assim dizer, exige do professor uma postura de constante aprendizado, que, para Mateus (2002), está relacionada à audácia e curiosidade ao propor o ensino da LI em uma versão comunicativa pós-estruturalista não mais focada em regras gramaticais que têm como guia o livro didático. E, por outro lado, e não menos importante, não enxergam as tecnologias digitais como "varas de condão".

Vale destacar que a maturidade pedagógica do profissional, postulada pelo autor supramencionado, não está diretamente relacionada às tecnologias digitais e seus inúmeros recursos, os quais podem vir a ser utilizados no contexto de ensino. Acreditase que essa maturidade é desenvolvida e solidificada a partir e durante os processos de formação, bem como da experiência de docência vivenciada pelo professor.

Retomando a apresentação das pesquisas na área de CALL, o trabalho de Costa (2014), embora não garanta que o uso didático das tecnologias digitais modifique o foco estruturalista do ensino de LI, pode ilustrar uma tentativa de romper com ele. $\mathrm{O}$ professor propõe o recurso AVA (Ambiente Virtual de Aprendizagem), para organizar as atividades trabalhadas em sala de aula, bem como a oportunidade de oferecer aos alunos o acesso em casa de conteúdos e atividades. A tela principal do AVA proporciona sete opções de acesso (as quais estão postas na língua materna): Principal, Perfil, Escola Virtual, Espaço do aluno, Biblioteca, Notícias, Contato. 
Os conteúdos são acessados por meio de hipertextos que conduzem a outras páginas específicas. A opção "Escola Virtual” oferece todo o conteúdo trabalhado, durante o ano letivo. Além disso, o aluno pode trabalhar as habilidades linguísticas disponibilizadas nos tópicos inerentes a cada conteúdo. Esse conteúdo está disposto na plataforma, por meio de hiperlinks, que vão conduzir a informações diversas, as quais são direcionadas pelo próprio leitor/aprendiz durante seu processo de aprendizagem de LI, aqui salientado.

Vale lembrar que as propostas de ensino da LI, em um contexto tecnológico digital, especificamente, por meio do AVA destacado acima, pressupõem a necessidade de uma formação docente voltada para os letramentos digitais, assim como postulado por Brito e Andrade (2017). Ou seja, utilizar recursos tecnológicos digitais no processo de ensino de LI demanda um saber diferente daquele que se constrói para o uso do livro didático, por exemplo. Pois, mais do que saber manusear um livro didático que já está pronto e foi pensado/elaborado por uma equipe visando o ensino da LI, o professor que se pré dispõe a utilizar o AVA, precisa ter a habilidade de "preparar" esse ambiente para o ensino, assim como enfatizado por Moran (2015).

Por essa razão Ribas (2016), enfatiza a necessidade de se desenvolver o letramento digital também durante os processos de formação continuada do professor. Para que ele desenvolva as habilidades - letramento digital - necessárias para o uso dos ambientes virtuais vistos como contextos de ensino.

Em outras palavras, assim como pontuado por Brito e Andrade (2017), a ausência do letramento digital adequado pode representar um entrave para o trabalho do professor no ambiente escolar provido de artefatos tecnológicos digitais. O que nos leva a pensar que esta seja a razão pela qual o professor opta, por vezes, em continuar trabalhando apenas com as tecnologias tradicionais, principalmente, o livro didático.

Outro fator que pode também vir a interferir na decisão de utilizar ou não as tecnologias digitais para o ensino de LI é a ausência do suporte técnico. Ou seja, em relação às condições técnicas disponíveis nas escolas, Chambers e Bax (2006), He, Puakponk e Lian (2015) salientam que essa é uma realidade que contribui para o desestímulo dos professores no que diz respeito ao uso de qualquer que seja a TDIC para o ensino da LI. Os autores afirmam que a falta de um suporte técnico apropriado parece ser um complicador para a utilização das tecnologias digitais - como os 
computadores conectados à internet nas escolas - como mediadoras do ensino e para que o professor consiga romper com o ensino tradicional da língua mediado apenas pelo livro didático, por assim dizer.

Por outro lado, Izquierdo et al. (2017) afirmam, sustentados em Egbert e Yang (2004) e Taylor e Gitsaki (2003), que existem evidências de que os professores de LI estão se dedicando para superar as dificuldades com o uso das tecnologias digitais no contexto público de ensino. Porém, segundo os autores, as propostas de ensino mediadas pelas TDIC em sala de aula ainda se encontram em uma fase inicial.

Apesar da supracitada assertiva não se referir diretamente ao nosso contexto de pesquisa, parece que compartilhamos algumas semelhanças, principalmente, se adotarmos como referência as fases de CALL descritas por Reis (2012), em relação à utilização dos computadores na sala de aula: i) introdução, após observada a relevância dos recursos tecnológicos digitais para o ensino de LE; ii) elaboração de materiais didáticos para o meio tecnológico digital, análise de cursos e de softwares e papel do professor em contexto online [...]; iii) análise das propostas e práticas relacionadas ao ensino da LE no contexto digital.

Quanto à primeira fase elencada pela autora supracitada, devemos inferir que a utilização dos computadores em sala de aula pressupõe o estabelecimento de objetivos, os quais o docente deseja alcançar durante sua prática didática, assim como os prováveis benefícios provenientes da utilização da tecnologia digital escolhida. Logo, devemos considerar que a utilização das tecnologias digitais está diretamente vinculada ao objetivo que se almeja. Além do exposto, deve-se lembrar que a clareza em estabelecer esse objetivo está diretamente vinculada à necessidade de formar professores que sejam capazes de avaliar os prós e contras do uso das tecnologias digitais em seu contexto de atuação. Apropriando-nos das palavras de Vian Júnior (2013, p.210-211):

[s]omos cada dia mais envolvidos pelas novas tecnologias e elas vão adentrando nossas relações sociais e nossos sistemas de relacionamentos e tecnologizando nossas rotinas. (...) Ao mesmo tempo em que não podemos estar alheios, também não podemos simplesmente adotá-las pelo simples fato de estarem presentes. (...) Em época de parafernálias tecnológicas como quadros interativos, aparelhos inteligentes, banda larga, Skype, conferencecalls, Ipads, Podcasts, quejandos e quetais, não basta apenas incorporá-los às práticas e distribuir Ipads em vez de livros didáticos se não há formação para tal. 
O evento da distribuição de tablets (RELATÓRIO DE GESTÃO, 2014), para os professores de ensino médio das escolas públicas de Minas Gerais, em 2011, parece ilustrar o conteúdo da citação acima. O Relatório de Gestão de 2014 afirma que a distribuição do citado artefato aos professores ocorreu de forma isolada, sem um trabalho de conscientização e incorporação do corpo docente a um provável projeto que incluísse os tablets como recurso pedagógico. O que nos faz retomar a importância de ser promover ainda durante a formação inicial dos professores de línguas, estudos teóricos-práticos voltados para o uso das tecnologias digitais em sala de aula.

Pois, pensar e efetivar uma formação preocupada com uma experiência didáticopedagógica voltada para o uso das tecnologias digitais poderá amenizar as situações vivenciadas pelos docentes, as quais foram descritas pelos pesquisadores das supracitadas teses e dissertações. Dessa forma, devemos reiterar a premissa dos autores mencionados nesta seção, especialmente, Vian Júnior (2013), que trata da inocuidade representada pela presença de recursos digitais nos contextos escolares se a ausência de um trabalho de formação do educador nesse sentido permanecer.

Não devemos, pois, como educadores que somos abster-nos de nosso compromisso com a educação. Conforme Leffa (2001), cabe ao professor refletir e decidir sobre a pertinência de cada recurso tecnológico digital como artefato pedagógico. E essa reflexão deve ser estimulada e efetivada, tanto nos ambientes de formação inicial, quanto naqueles destinados à formação continuada. A fim de contribuir para a formação do professor na proposição das tecnologias digitais para o ensino da LI, propomos uma análise do contexto escolar de várias escolas públicas estaduais.

\section{Metodologia}

Visando buscar informações sobre a hipótese levantada, de que os professores de LI, de um município do Sul de Minas Gerais, ainda não utilizam as tecnologias digitais, de forma crítico-reflexiva, em suas práticas diárias, decidimos ir a campo e pesquisar a situação do ensino de LI. Vistamos as escolas e após explicarmos nossas intenções de pesquisa e comentarmos sobre a proposta de uma oficina a ser oferecida a eles após a 
realização do trabalho encontramos doze (12) professores interessados em contribuir com nosso trabalho e assim se tornaram sujeitos da pesquisa.

A eles, aplicamos um questionário o qual era composto de quatorze (14) perguntas objetivas com variação entre duas (2) e cinco (5) alternativas de respostas e três subjetivas. O questionário tinha como objetivo principal obter informações sobre o panorama de ensino de LI nas escolas públicas, levando em consideração seu processo e a formação acadêmica do professor. A escolha do questionário, como instrumento de geração de dados e como forma de aprofundar conhecimentos sobre as respectivas experiências dos participantes da pesquisa, teve como base os preceitos de Gunther (2003). O autor afirma ser o questionamento aos indivíduos uma das três maneiras de conhecer e entender o comportamento humano, como agem e o que pensam. Quanto ao tratamento dos dados gerados, fundamentamos na teoria da Análise de Conteúdo de Laurence Bardin (2009).

Portanto, a investigação que embasa este artigo caracteriza-se como uma pesquisa qualitativa exploratória de cunho interpretativista. Em relação aos procedimentos técnicos, podemos afirmar que trata-se de uma pesquisa de campo, delineada como estudo de caso, tendo como cenário sete (7) escolas públicas de um município do Sul de Minas Gerais, localizadas em diversos pontos, desde a parte central até a periferia.

Sob esse viés metodológico os dados foram coletados com anuência dos diretores das escolas, dos professores de língua inglesa envolvidos e do comitê de ética da instituição a que a investigação está vinculada, via Plataforma Brasil/MEC.

Quanto à metodologia de análise, apresentamos a seguir, um recorte da forma em que sistematizamos a análise a partir da criação de indexadores que tinham como objetivo primário responder as seguintes perguntas de pesquisa:

i) Quais as prováveis lacunas existentes na utilização das TDIC para o ensino da LE?

ii) Que práticas são ressaltadas pelos docentes em relação ao ensino da língua inglesa?

Parece importante esclarecer que, antes da apresentação e discussão de cada dado, fizemos a opção de apresentar um quadro com o objetivo de correlacionar os indexadores, abaixo elencados, à respectiva pergunta de pesquisa e à respectiva questão do questionário.

Indexadores:

1 Estratégias didático-pedagógicas utilizadas. 
2 Utilização da tecnologia em sala de aula.

Tabela 1- Indexador 1

\begin{tabular}{|cc|c|}
\hline Indexador & Pergunta de Pesquisa & Questão do questionário \\
\hline Estratégias didático- & Quais as prováveis lacunas \\
pedagógicas utilizadas & existentes na utilização \\
das TDIC para o ensino da & $\begin{array}{c}\text { Quais dos artefatos tecnológicos abaixo você } \\
\text { julga necessário para uma aula de Língua } \\
\text { LE? }\end{array}$ & $\begin{array}{c}\text { Inglesa? } \\
\text { Faça um pequeno relato de como acontecem } \\
\text { suas práticas didáticas em sala de aula. }\end{array}$ \\
\hline
\end{tabular}

Fonte: Questionário utilizado como instrumento de coleta de dados (2018).

O segundo indexador abaixo foi criado a partir dos dados que demonstram que a formação do professor para o uso das TDIC como recursos mediadores do ensino de LI, ainda não é uma realidade em muitos contextos. Observe na Tabela 2 que o foco passa a ser os aspectos teórico-metodológicos a que os professores foram expostos durante a graduação e na Tabela 3 o foco destina-se a oficina que será preparada para ajudá-los:

Tabela 2 - Indexador 2

\begin{tabular}{|c|c|c|}
\hline Indexador & Pergunta de Pesquisa & Questão do questionário \\
\hline $\begin{array}{c}\text { Utilização da } \\
\text { tecnologia em sala } \\
\text { de aula }\end{array}$ & $\begin{array}{c}\text { Que práticas são ressaltadas pelos } \\
\text { docentes em relação ao ensino da }\end{array}$ & $\begin{array}{c}\text { A quais aspectos teórico-metodológicos } \\
\text { esses professores foram expostos durante } \\
\text { sua graduação? }\end{array}$ \\
$\begin{array}{c}\text { língua inglesa? } \\
\text { Faça um pequeno relato de como }\end{array}$ \\
$\begin{array}{c}\text { acontecem suas práticas - didáticas em sala } \\
\text { de aula }\end{array}$ \\
\hline
\end{tabular}

Fonte: Questionário utilizado como instrumento de coleta de dados (2018).

Tabela 3 - Indexador2

\begin{tabular}{|c|c|c|}
\hline Indexador & Perguntas de pesquisa & Questão do questionário \\
\hline Utilização da & Quais as prováveis lacunas & Que aspectos você gostaria que fossem abordados \\
tecnologia em sala de & existentes na utilização das \\
aula & em uma oficina para reflexão sobre práticas \\
& TDIC para o ensino da LE? & ligadas ao uso das tecnologias digitais? \\
\hline
\end{tabular}

Fonte: Questionário utilizado como instrumento de coleta de dados (2018).

A partir desses indexadores e dos outros que não serão apresentados no escopo desse artigo chegou-se a ideia de apresentar aos sujeitos colaboradores da geração de dados uma proposta de oficina a ser aprimorada pelos interessados e aplicada no ano de 2019. O esboço dessa oficina será apresentado na próxima seção após a sistematização e discussão dos dados desse recorte investigativo. 


\section{Resultados e Discussão}

Nesta seção fizemos a opção de apresentar, um recorte das informações viabilizadas pelo questionário de forma categorizada. Para tanto, lançamos mão de quadros os quais apresentam as respostas dos colaboradores da pesquisa às perguntas presentes no instrumento de geração de dados. Os dados serão apresentados seguindo os indexadores 1 e 2, respectivamente, de forma a estabelecer um diálogo com a teoria e anunciados visando responder as perguntas de pesquisa apresentadas na seção anterior.

Começaremos pelo indexador 1 - Estratégias didático-pedagógicas utilizadas pelos professores. Ao se pensar nessas estratégias levando em consideração o uso das tecnologias digitais e de sua importância para a prática docente, fizemos o levantamento, via questionário, dos artefatos tecnológicos assinalados pelos participantes utilizados como materiais em suas aulas.

Verificamos que todos os participantes de pesquisa assinalaram, pelo menos, um tipo de tecnologia, entre elas aparelho de som, computador, CDs de áudio, datashow. Porém dá forma em que os dados foram gerados não é possível afirmar que essa escolha se estabeleça a partir de ou embasada em uma fundamentação teórica ou um planejamento que possa sustentar a utilização desses artefatos. É interessante ressaltar que a despeito de terem assinalado os artefatos tecnológicos como mediadores do ensino da LI, no momento em que foram fazer seus relatos, elencados no Quadro 1 a seguir, só mencionam o livro didático e a lousa e nenhum outro artefato tecnológico.

Essa consideração vem ao encontro da assertiva de Chen (2008) de que boa parte dos professores independente do tempo de atuação parecem não utilizarem as tecnologias - digitais ou não - de forma fundamentada. Além disso, coadunam com Izquierdo et al. (2017), sustentados em (EGBERT; YANG, 2004; TAYLOR; GITSAKI, 2003) de que as propostas de ensino mediadas pelas TDIC, nas escolas públicas, ainda se encontram em uma fase inicial (Quadro 1).

Quadro 1-Faça um pequeno relato de como acontecem suas práticas-didáticas em sala de aula. Respostas de (P4), (P6), (P9).

Nas minhas aulas tento usar o livro didático sempre (Way toEnglish). Chego na sala, faço chamada, organizo os alunos e faço perguntas sobre o que eles já sabem acerca do assunto tratado no texto (P4alguns meses de atuação).

Inicio as aulas com os procedimentos obrigatórios como chamada. Normalmente utilizando o Livro 


\section{Didático, corrigindo exercícios anteriores, etc. (P6 - seis meses de atuação).}

As aulas geralmente são na lousa mesmo, com exercícios mesclados: gramática, oralidade, vocabulário, mas, no geral, há um grande desinteresse dos alunos(P9 - nove anos de atuação).

Fonte: Questionário utilizado como instrumento de coleta de dados (2018).

Tais relatos podem ser vistos como um contra exemplo do comportamento esperado dos professores de LI, em termos de estratégias didático-pedagógicas que tenham como foco o uso das TDIC. Atualmente, com um contexto social em que os alunos já são considerados conhecedores das TDIC, espera-se dos professores uma ressignificação de conhecimentos que não lhes permita mais focar no ensino da gramática e nem atribuir ao livro didático a proeminência na proposição das atividades cotidianas em sala de aula (MATEUS, 2002).

Isto posto, vale ressaltar novamente os estudos de Chapelle (1990, p.199) quando pontua que "os professores precisam entender como CALL- Computer Assisted Language Learning - pode ser melhor utilizado para oferecer a efetiva aprendizagem aos alunos", o que perpassa pela urgência de os professores se informarem em relação às contribuições que as TDIC podem proporcionar e fazer uso delas em sala de aula.

No que diz respeito ao conteúdo da afirmação de Chapelle, Lévy (1999) declara que estamos imersos em um mundo tecnológico digital e não podemos nos omitir do nosso papel de educador, que é preparar cidadãos para viver e conviver com o que está posto na e pela sociedade. Um exemplo que elucida as considerações de Chapelle e Lévy é o relato do P7 em relação a pergunta do quadro 1:

\section{Quadro 2 - Resposta do (P7)}

Todo bimestre, a nossa avaliação é feita on-line. [...] fica disponível 15 dias para que os alunos façam quantas vezes forem necessárias. Sabendo da dificuldade de alguns para acessar internet, levo-os, pelos menos, duas vezes à sala de informática para fazerem as provas. Além disso, tento fazer trabalhos mais práticos, como gravação de clipes musicais, programas de culinária e entrevistas, etc (P7).

Fonte: Questionário utilizado como instrumento de coleta de dados (2018).

Desta forma, percebemos que a maioria dos professores, sujeitos desta investigação, ainda tem muito a desbravar quanto à utilização pedagógica dos artefatos digitais, pela carência de materiais para esse fim e pela ausência de formação inicial e 
continuada no tocante a essa questão. Por esta razão, Reis (2012) salienta a importância de o professor aprimorar seus conhecimentos a respeito da área de CALL e seus benefícios para o ensino da LI.

Portanto, parece importante pontuar que, embora os excertos dos professores (quadro 1) não estejam diretamente ligados a lacunas de sua formação inicial e continuada, pensamos que a prática docente, ali posta, é resultado desses processos formativos, o que novamente destaca a necessidade e importância da efetivação da oficina pensada para ser oferecida após esta investigação. Vale retomar que as lacunas em relação ao uso das TDIC fazem-se perceptíveis nos relatos dos professores quando eles não as mencionam em suas práticas diárias.

Desta forma, ao pensarmos no uso didático-pedagógico das tecnologias digitais, pensamos também ser necessário que se tenha embasamento teórico sistemático, capaz de fundamentar as escolhas do professor e a definir como, onde, para quem e com que objetivos irá utilizar um determinado site ou aplicativo como mediadores do ensino da LI. Isso posto, ressaltamos a importância da formação continuada, bem como da oficina que devemos oferecer aos participantes da presente pesquisa, no sentido de contribuir para esse embasamento didático-pedagógico.

Em relação ao indexador 2 - Utilização da tecnologia em sala de aula - o excerto abaixo nos remete a tentativa que parece ter sido feita, mas que nos parece ser sem nenhuma fundamentação teórica oriunda de formação inicial ou contínua. Ou seja, verificamos que foi uma tentativa isolada de um profissional, baseada na boa vontade do professor que ousa novos rumos para o ensino da LI (rever também o quadro 2).

Quadro 3- Como começou a lidar com o computador para fins educativos?Resposta de (P7) Em minha casa, sozinho (a) ou com ajuda de alguém (P7).

Fonte: Questionário utilizado como instrumento de coleta de dados (2018).

Desta forma, a fim de minimizar todo esse cenário do "não" uso criterioso das TDIC, ou pelo menos retornar à comunidade de forma a auxiliá-la em relação às prováveis escolhas docentes, foi perguntado aos professores participantes da pesquisa que aspectos eles gostariam que fossem abordados em uma oficina com o objetivo de reflexão e implementação de novas práticas didáticas, sobretudo, em relação às TDIC. 
Daremos destaque aos relatos de P2, P3, P6, P8, P12 a respeito de suas limitações e dúvidas em relação ao uso das tecnologias digitais como artefato de ensino da LI (Quadro 4). Os excertos evidenciam o interesse dos professores em conhecer e se adequarem à aprendizagem da língua. Vale destacar que o tempo entre parênteses corresponde ao tempo de atuação como docente, haja vista a correspondência que acreditamos haver entre a experiência de sala de aula e o contato com as tecnologias digitais como artefato pedagógico.

Quadro 4 - Que aspectos você gostaria que fossem abordados diante da possibilidade de uma oficina para o ensino da Língua Inglesa?Respostas dos P2, P3, P6, P8, P10, P12.

Creio que os aspectos a serem abordados como conhecimento de plataformas e de como usar a tecnologiacomo ferramenta viável para educação na escola pública já estaria de bom tamanho (P2) (3 anos).

Gostaria de discutir um pouco sobre possíveis avaliações mediadas pelo computador. Confesso que já pensei sobre esta questão mas tenho limitações para desenvolver (P3) (20 anos).

Uso consciente dos recursos digitais. Disponibilizar ferramentas para uso pedagógico em sala de aula (P6) (6 meses).

Gostaria de aprender melhor a elaborar materiais audiovisuais para minhas aulas (P8) (3 meses). Como utilizar, como desenvolver material para apoio (P10)( 10 anos).

Baixar arquivos de sites, gravações, podcasts, utilização de aplicativos úteis para elaboração de materiais de inglês (P12) (17 anos).

Fonte: Questionário utilizado como instrumento de coleta de dados (2018).

No sentido de discutir e apresentar as evidências relacionadas aos supracitados excertos destacamos, no quadro acima, em negrito, algumas palavras que demonstram o interesse dos professores em introduzir as tecnologias digitais e desenvolver práticas diferenciadas para o ensino da LI. Reis (2012, p. 19) as classifica como "fase de inserção das tecnologias na sala de aula de língua estrangeiras".

Tendo em vista os excertos, parece que ainda estamos numa fase inicial no uso dos artefatos tecnológicos, fato esse que condiz com prováveis lacunas em relação ao uso operacional e funcional das tecnologias digitais, no contexto de pesquisa em evidência.

Destaca-se Baptista (2014), ao pontuar que, mesmo os docentes mais jovens, dos quais se espera maior contato com os artefatos tecnológicos digitais, demonstram dificuldades e limitações quanto ao uso das tecnologias digitais como recursos didáticos pedagógicos. Se considerarmos os relatos, atentos ao tempo de atuação, dispostosno 
quadro acima, podemos constatar que parece ainda não haver, nas salas de aulas desses sujeitos de pesquisa, um trabalho fundamentado na área de CALL.

No relato de P2 fica evidente sua limitação de como utilizar o que a tecnologia oferece para o ensino da LI e, por outro lado, seu interesse em aprender. Essa parece ser a realidade de muitos professores das escolas públicas, que, muitas vezes, por razões diversas, não fazem uso dos computadores.

No relato de P3 fica claro seu anseio em compartilhar dúvidas e limitações com outros docentes na tentativa de atingir uma prática diferenciada. Nesse sentido, devemos inferir a prática de discussão coletiva defendida por (KESSLER, 2006; LÉVY, 2010; SANTOS, 2012) como forma de fundamentar o uso das tecnologias digitais para fins pedagógicos e de seus respectivos resultados.

Trata-se de uma estratégia de formação que, talvez, pudesse ser adotada pelas escolas, pois os professores poderiam trocar experiências e problematizar hipóteses de uso desses artefatos. Logo, consonante a (BAX, 2003, 2011; VIEIRA, 2010), se não houver formação do profissional da educação, pouco valerão os investimentos em recursos tecnológicos. Em relação à essa assertiva, devemos pontuar que a formação inicial ou continuada do professor para a área de CALL parece ser um diferencial para uma prática contundente de ensino da LI.

Contudo, a prática evidenciada em nosso contexto de investigação não condiz com uma formação docente voltada para a área de CALL, supramencionada. Pois, em relação ao que foi disposto nos dados desta investigação, devemos concluir que existem tentativas de contextualizar o ensino da LI ao cotidiano do aluno ou, pelo menos, não focar apenas de forma estruturalista o ensino da língua.

Por outro lado, parece não haver um trabalho fundamentado para o uso das TDIC como recursos mediadores do ensino da LI. Apesar das supracitadas narrativas evidenciarem estratégias de desviar do ensino tradicional da LI - músicas, séries, filmes, não há um relato de uso das TDIC, nem tampouco de objetivos, estratégias e benefícios a serem alcançados com o uso desse recurso. Isso nos levar a concluir que os professores de LI, neste contexto de investigação ainda têm um longo caminho pela frente no sentido de utilizar de forma contundente as TDIC.

Um dos caminhos pode ser determinado pela participação na oficina que será oferecida. O objetivo da oficina intitulada "Plano de ação para o uso das TDIC no 
ensino de $L I^{\prime \prime}$ é ajudá-los a conhecer e talvez utilizar as mídias digitais como recursos mediadores do ensino-aprendizagem da língua inglesa. Mas, caberá a cada professor, em momento oportuno refletir a respeito da proficuidade de cada sugestão ao seu próprio contexto podendo ser expandidas por eles caso considerem pertinente.

A oficina constará de $16 \mathrm{~h}$, divididas em dois dias durante manhã e tarde. $\mathrm{Na}$ manhã do primeiro dia deveremos propor um aperfeiçoamento teórico por meio da leitura de textos sobre letramento digital e contribuições da área de CALL para o uso das TDIC como recursos mediadores do ensino da LI.

Os professores deverão se dividir em grupos menores para leitura, discussão e escrita de um parágrafo que visa entrelaçar suas respectivas concepções ao que foi proposto sobre letramento digital. Deverão abordar questões sobre o que poderia ser modificado em seu cotidiano escolar tendo como pano de fundo a área de CALL e, partindo do pressuposto de que o letramento digital parece inerente ao perfil do cidadão contemporâneo. Em seguida, cada grupo deverá apresentar suas respectivas colocações abrindo espaço para discussões e considerações diversas.

A justificativa para essa proposta de trabalho perpassa pela importância da construção do conhecimento em grupo, além de fundamentar o uso das TDIC como mediadoras do ensino da LI. Parece fundamental que os professores diferenciem tecnologias digitais daquelas que já se cristalizaram ao ensino da LI, como o uso de aparelho de som, por exemplo. Já que os professores participantes demonstraram insegurança e indagações quanto ao uso das tecnologias digitais.

Em um segundo momento da oficina será abordado a questão prática do uso da TDIC. Momento este, em que os professores irão vivenciar o planejamento, execução e avaliação de algumas atividades online. Algumas delas sugeridas por Barcelos (2016, p. 44)

$>$ <http://www.podcasts ${ }^{1}$ english.com/index.shtml>;

$<$ http://learnenglish.britishcouncil.org/en/elementary-podcasts>;

<http://learnenglish.voanews.com/podcast/0.html>;

$<$ http://www.bbc.co.uk/podcasts/series/tae>;

"Podcast é o nome dado ao arquivo de áudio digital, frequentemente em formato MP3 ou AAC (este último pode conter imagens estáticas e links), publicado através de podcasting na internet e atualizado via RSS" consonante a Barcellos (2016, p. 44). 
$<$ http://.techthought.com/technology/51-education-podcasts-for-the-21-stcentury-teacher/>.

O "Padlet", um site gratuito que permite a criação de um mural virtual com postagem de fotos, textos e comentários das postagens de outros colegas, também poderá ser explorado. Bem como os sites sugeridos pelos participantes da pesquisa:

$><$ https://learnenglishteens.britishcouncil.org/ar/uk-now/read-uk/shakespeare>;

$><$ https://learnenglishteens.britishcouncil.org/grammar-vocabulary/vocabularyexercises/vegetables>;

$><$ https://learnenglishteens.britishcouncil.org/skills/speakinleng-skillspractice/meeting-people>.

\section{Considerações finais}

Neste artigo, evidenciamos dados que comprovam a hipótese levantada, de que os professores ainda não utilizam as tecnologias digitais como mediadoras do ensino da LI, e quando as utilizam fazem sem um objetivo claro e fundamentado em conhecimentos teóricos. Constatamos que os professores ainda usam o livro didático como guia principal de suas práticas e que existe uma dificuldade em trabalhar com os diversos recursos provenientes das TDIC, tais como computadores e tables conectados a internet. Além disso, parece não existir um trabalho de formação continuada direcionado aos colaboradores na geração de dados desta pesquisa. Formação essa que vise promover e facilitar a reflexão em torno do uso das TDIC em sala de aula.

Mesmo assim, alguns se arriscam a utilizar algumas práticas utilizando as TDIC como recursos mediadores no ensino de LI. Contudo, afirma não se sentirem seguros para desenvolver um trabalho de maior abrangência com esses artefatos. O que existem são apenas tentativas isoladas de uso do computador. Portanto, é possível afirmar que não há descrição de uma prática contundente em relação aos meios tecnológicos digitais. E assim é possível conjecturar que os professores deste contexto investigativo ainda não sabem como seguir por esse caminho de forma a oferecer um ensino significativo aos seus alunos. 
Em suma, há evidências da fragilidade na formação inicial e continuada dos professores que contribuíram com essa investigação. Com o intuito de minimizar esse problema, por meio deste artigo e da oferta da oficina, acreditamos poder contribuir com a formação crítico reflexiva dos professores em torno dos preceitos de CALL utilização das tecnologias digitais como artefato pedagógico - bem como com a formação docente.

\section{REFERÊNCIAS}

BAPTISTA, J. B. Reflexões de professores de inglês em formação inicial sobre o uso de novas tecnologias. Revista Brasileira de Linguística Aplicada, Belo Horizonte, v. 14, n. 3, p. 533-552, 2014.

BARCELLOS, A. M. F. "I can do it": Vencer limitações pessoais no uso do Inglês. In: CUNHA, A. G. MICCOLI, L. Faça a diferença: ensinar língua estrangeira na educação básica. São Paulo: Parábola, 2016.p. 38-47.

BARDIN, L. Análise de conteúdo. Lisboa: Edições 70, 2009.

BAX, S. CALL - past, present and future. In: System, Linkoping, v. 31, p. 13-28, 2003.

BAX, S. Normalisation revisited: the effective use of technology in language education. In: International Journal of Computer-Assisted Language Learning and Teaching, Luton, v. 1, n. 2, p. 1-15, 2011.

BRAGA, D. B. A comunicação interativa em ambiente hipermídia: as vantagens da hipermodalidade para o aprendizado no meio digital. In: MARCUSCHI, L. A.; XAVIER, A. C. S. (Org.). Hipertexto e gêneros digitais: novas formas de construção do sentido. Rio de Janeiro: Lucerna, 2004.p. 144-162.

Ambientes digitais: reflexões teóricas e práticas. $1^{\circ}$ ed. São Paulo, 2013.

BRITO, Glaucia da Silva; DE ANDRADE, Mayara Quadros. Letramento digital e as práticas no Ambiente Virtual de Aprendizagem (AVA). SUCEG - Seminário de Universidade Corporativa e Escolas de Governo, [S.1.], v. 1, n. 1, 2017. p. 17-29, dec. Disponível em: 〈http://anais.suceg.ufsc.br/index.php/suceg/article/view/11>. Acesso em: 16 junho 2019. 
CARDOSO, A. C. S. formação inicial de professores de inglês para o uso das tecnologias digitais: uma pesquisa-ação no contexto do estágio supervisionado. 2015. 235 p. Tese (Doutorado em Linguística Aplicada) - Universidade Federal do Rio de Janeiro, Rio de Janeiro, 2015.

CHAMBERS, A.; BAX, S. Making CALL Work: Towards normalization. In: System, Linkoping,v.34, n. 4, p. 465-497, 2006.

CHAPELLE, C. The discourse of computer-assisted language learning: toward a context for descriptive research. TESOL Quarterly, Washington, v. 24, n. 2, p. 199-225, 1990.

CHEN, C. Why do teachersnotpracticewhattheybelieveregardingtechnologyintegration? In: The Journal of Educational Research, Washington, v. 102, n. 1, p. 65-75, 2008.

COSCARELLI, C. V. Alfabetização e letramento digital. In:COSCARELLI, C. V.; RIBEIRO, A. E. (Org.) Letramento digital: aspectos sociais e possibilidades pedagógicas. 2. ed. Belo Horizonte: Autêntica, 2011.p. 25-40.

COSTA, W. M. As tecnologias digitais da informação e comunicação no ensino da língua inglesa. João Pessoa: Universidade Federal da Paraíba, 2014.

EGBERT, J.; YANG, Y. F. "Mediating the digital divide in call classrooms: promoting effective language tasks in limited technology contexts." In: ReCALL, Cambridge, v. 16, p. 280-291, 2004.

GÜNTHER, H. Como elaborar um questionário. Brasília: UNB, (Planejamento de Pesquisa nas Ciências Sociais, 1). 2003.

HE, B.; PUAKPONG, N.; LIAN, A. Factors Affecting the normalization of CALL in Chinese Senior High Schools. Computer Assisted Language Learning, Antwerp, v. 28, n. 3, p. 189-201, 2015.

HUBBARD, P. Linguistics and the Teaching of English as a Second/Foreign Language. Disponível em: http://www.stanford.edu/class/linguist289/call1.htm,2004. Acesso em 10/08/2004. 2004

IZQUIERDO, J. et al. Teachers' use of ICTs in public language education: evidence from second language secondary-school classrooms. In: Comunicar, México, v. 25, n. 50, p. 33-41, 2017. 
KESSLER, G. Assessing CALL teacher training: what are we doing and what could we do better? In: HUBBARD, P.; LÉVY, M. (Ed.). Teachereducation in CALL. Amsterdam: J. Benjamins, 2006.

KLEIMAN, A. B.; MORAES, S. E. Agenda de pesquisa e ação em linguística aplicada: problematizações. In: CELANI, A. (Ed.). Linguística aplicada na modernidade recente. São Paulo: Parábola, 2013. p. 39-58.

LEFFA, V. O professor de línguas [estrangeiras]: construindo a profissão. Pelotas: Educat, 2001.

LÉVY, M. Cibercultura. São Paulo: Ed. 34, 1999. (Coleção TRANS). Computer-assisted language learning. Oxford: Oxford University, 1997. . Cibercultura. São Paulo: Editora 34, 2010.

LEVY, M.; HUBBARD, P. Why call CALL "CALL"? Computer Assisted Language Learning, 18(3):143-149. 2005.

MATEUS, E. Educação contemporânea e o desafio da formação continuada. In: GIMENEZ, T.(Ed.).Trajetórias na formação de professores de línguas. Londrina: Editora da UEL, 2002. p. 3-14.

MORAN, J. Manuel. Educação Inovadora na sociedade da informação. 2015 Disponível em: http://files.oficinacriarsites.webnode.com.br/200000030-b85a2b9541/moran.PDF. Acesso em: 16 junho 2019.

REIS, S. C. As fases de pesquisas sobre Computer Assisted Language Learning (CALL) no Brasil: identificação do estado da arte. In: Revista Horizontes de Linguistica Aplicada, Santa Maria, v. 11, n. 1, p. 15-36, 2012.

RELATÓRIO ANUAL (2011-2014). Disponível em: $<$ https://www.educacao.mg.gov.br/ images/documentos/RELATORIO_GESTAO_COMPLETO_WEB.pdf>. Acesso em: 2 abr. 2018.

RIBAS, F. C. Formação de professores de língua inglesa a distância: atividades de reflexão em fóruns de discussão. Fórum Linguístico, Florianópolis, v. 13, n. 1, p. 1037 1054, 2016.

SAMPAIO, M. N.; LEITE, L. S. Alfabetização tecnológica do professor. 9. ed.Petropólis: Vozes, 2011. 
SANTOS, A. I. Educação aberta: histórico, práticas e o contexto dos recursos educacionais abertos. In: SANTANA, B.; ROSSINI, C.; PRETTO, N. L. (Org.). Recursos educacionais abertos: práticas colaborativas e políticas públicas. Salvador: Edufba; São Paulo: Casa da Cultura Digital. 2012. p. 71-90.

TAYLOR, R. P.; GITSAKI, C. Teaching WELL in a computer less classroom. Computer Assisted Language Learning, Antwerp, v. 16, p. 275-294, 2003.

VETROMILLE-CASTRO, R. O professor como facilitador virtual: considerações teórico-práticas sobre a produção de materiais para aprendizagem via web ou mediada por computador. In: LEFFA, V. J. (Org.). Produção de materiais de ensino: teoria e prática. Pelotas: Educat, 2003.

VIAN JÚNIOR, J. R. O. Universidade Federal do Rio Grande do Norte (UFRN). In: SILVA, K. A.; ARAGÃO, R. C. (Org.). In: Conversas com formadores de professores de línguas: avanços e desafios. Campinas: Pontes, 2013. p. 201-213.

VIEIRA, A. A. S. Integração de web tecnologia em atividade de ensino: do Proinfo integrado à aula de língua inglesa. In: Contexturas, São José do Rio Preto, v. 17, p. 95$112,2010$. 